\title{
Toward an Integrated, Systemic, and Sustainable Model of Transformational Family Engagement: The Case of the Kentucky Statewide Family Engagement Center
}

\author{
Danielle M. Perry * and Joanna Geller (D)
}

check for

updates

Citation: Perry, Danielle M., and Joanna Geller. 2021. Toward an Integrated, Systemic, and Sustainable Model of Transformational Family Engagement: The Case of the Kentucky Statewide Family Engagement Center. Social Sciences 10 : 402. https://doi.org/10.3390/ socsci10100402

Academic Editor: Steven B. Sheldon

Received: 31 July 2021

Accepted: 12 October 2021

Published: 19 October 202

Publisher's Note: MDPI stays neutral with regard to jurisdictional claims in published maps and institutional affiliations.

Copyright: (c) 2021 by the authors. Licensee MDPI, Basel, Switzerland. This article is an open access article distributed under the terms and conditions of the Creative Commons Attribution (CC BY) license (https:// creativecommons.org/licenses/by/ $4.0 /)$.
Metropolitan Center for Research on Equity, Transformation of Schools, New York University, New York, NY 10012, USA; joanna.geller@gmail.com or Joanna.geller@nyu.edu

* Correspondence: Danielle.perry@nyu.edu

\begin{abstract}
Transformational family engagement fundamentally changes relationships between families and schools and interrupts deeply held beliefs about low-income, Black, Latinx, Indigenous, or immigrant families, each of which are rooted in systems of racism, classism, sexism, xenophobia, and their intersections. In this paper, we use a community-based collective impact theoretical framework to better understand how the KY Collaborative is aligned with transformational family engagement strategies and promotes and implements systemic, statewide evidenced-based family engagement policies and practices. We present data from interviews with KY Collaborative partners, observations of KY Collaborative events and activities, and survey data. Key findings suggest the KY Collaborative leverages each regional partner's strengths to break through historical barriers that fail to acknowledge the critical role families play both within and outside of schools. Their collective programs and services demonstrate a commitment to strengthening families, building capacity amongst schools and educators, and supporting communities to achieve educational equity. Our findings present implications for other statewide family engagement centers and community-based collaborations for transformational family engagement by highlighting the ways in which the KY Collaborative develops bottom-up leadership, builds dual capacity, shifts power, attends to policy change, and diffuses shared messages, visions, and practices statewide.
\end{abstract}

Keywords: transformative family engagement; collective impact; SFEC; model

\section{Introduction}

In 2018, the Global Family Research Project authored a paper for the Carnegie Corporation, whose purpose was to define and chart an agenda toward "next generation family engagement". The authors asserted:

We define next generation family engagement as moving from where we are now-a scattered, marginal, and unaligned set of programs and policies - to more strategic and systemic approaches to family and community engagement in and out of school and from birth through young adulthood.

Despite a massive body of research on family engagement, widespread district, state, and federal family engagement policies, and a proliferation of school- and communitybased family engagement programs, equitable and impactful family-school partnerships tend to occur in isolated pockets, for instance, in schools with an exceptional leader or a mission-driven staff (Ishimaru 2020; Montemayor 2019). Research is needed on how family engagement can become embedded in systems and structures, integrated into the everyday functioning of schools and districts, and sustained with stable resources (Ishimaru 2020; Mapp and Bergman 2019).

The 2018 federal investment in statewide family engagement centers (SFECs) offers an opportunity to learn how family engagement can become more systemic, integrated, and sustainable. In 2018, the U.S. Department of Education awarded 5-year grants to 12 states 
ranging from three to five million dollars. The purpose of the grant is to "provide technical assistance and training to state educational agencies (SEAs) and local educational agencies (LEAs) in the implementation and enhancement of systemic and effective family engagement policies, programs, and activities that lead to improvements in student development and academic achievement" (US Department of Education).

The Prichard Committee for Academic Excellence is the lead grantee for the Kentucky Statewide Family Engagement Center, otherwise known as the "Kentucky Collaborative". The Prichard Committee is a nationally recognized, independent, non-partisan citizen's advocacy organization based in central Kentucky. The organization studies priority issues and informs the public and policy makers about best practices and engages citizens, business leaders, families, students, and other stakeholders in a shared mission to move Kentucky to the top tier of all states for education excellence. The Prichard Committee has operated the Commonwealth Institute for Parent Leadership (CIPL), which builds families' knowledge, skills, and power related to improving public education, for nearly forty years.

In addition to the Prichard Committee, the KY Collaborative includes three regional partner organizations that each offer a variety of programming and services for children, young people, and families throughout their regions. The regional partners include Learning Grove in Northern Kentucky; Partners for Education, which is situated in Berea College, in the Appalachian region; and the National Center for Families Learning (NCFL) located in Louisville. The Kentucky Department of Education is an additional partner.

According to the Dual-capacity Building Framework, effective home-school partnerships require three organizational conditions. First, family engagement must be systemic, meaning leaders across the organization must communicate a commitment to family engagement and allocate the necessary resources for it. Second, family engagement must be integrated, or in other words, "embedded in all strategies", including staff recruitment, professional development, strategic planning, etc. Third, family engagement must be sustained with resources and infrastructure, including funding, leadership positions, and written policies and procedures. Yet, few models illustrate these organizational conditions in action. The KY Collaborative offers a unique opportunity for learning about how to build the organizational conditions for family engagement because its promise is to build a "groundswell movement", with leaders across the state embracing family engagement, supporting schools to integrate family engagement into core activities, and establishing the will for resources and policies to sustain family engagement.

In this paper, our purpose is to illustrate successes and challenges in developing a collaborative, community-based, and equitable statewide model for transformational family engagement. We begin by providing more detail about the Kentucky Collaborative. We then discuss literature on community-based and collaborative approaches to transformational family engagement, including the shortcomings and critiques of previous efforts.

\subsection{The Kentucky Collaborative}

The KY Collaborative is:

"a network of families, schools, districts and community partners focused on increasing open communication, learning opportunities, and shared decisionmaking power across the Kentucky education system. We share a unified voice in advocating for family leadership and effective family-school-community partnerships." (The Prichard Committee 2021)

It's ultimate goals are to increase students' literacy, development, and academic achievement, particularly with more children entering kindergarten ready to learn and more students exhibiting improvement in reading at the 3rd grade. Student college and career readiness has emerged as an additional goal over the course of the project.

The partner organizations work together to conduct trainings for families, educators, administrators, and community partners; develop parent leadership; manage a family engagement online resource hub; reduce policy and practice barriers to family engagement; support a statewide Learning Network and Advisory Council; and highlight and expand 
family engagement programs that work. They implement these activities through a tiered approach, where Tier 1 includes universal information dissemination, Tier 2 includes targeted, high-impact and evidence-based services; and Tier 3 includes intense evidencebased practices.

The partners share five stated beliefs, which are grounded in racial justice and equity:

1. Racism has been and continues to be a barrier for students of color and must be actively addressed.

2. When families, educators, and community organizations have strength-based mindsets and the confidence, capabilities, and connections to partner, high-quality, equitable, and inclusive education becomes the shared responsibility of families, schools, and communities.

3. Family engagement should be culturally responsive and sustaining: families and educators' partner to honor the lived experiences of all students, especially students of color, emergent bilingual students, students with disabilities, and economically disadvantaged students.

4. Parent leadership, voice, and decision-making is essential for influencing schools, supporting schools, and holding schools accountable.

5. Policy matters: Student success depends on access to reliable internet, neighborhoods free of violent policing, and affordable and quality early care and education.

The five partner organizations meet weekly to share updates, innovative practices in their regions, and plan and discuss collective initiatives. Additionally, an advisory council, consisting of families, school staff, KDE staff, business partners, and other communitybased organization staff meets monthly. The advisory council guides the direction of the KY Collaborative, including discussions about what families, students, and educators say is and is not working, developing a theory of change, and linking family engagement with other education efforts. Finally, the Learning Network meets monthly to learn best practices in family engagement. The Learning Network includes the advisory council, as well as others who are interested in learning more about family engagement. Table 1 illustrates the core activities of the KY Collaborative, as well as their anticipated short-term outcomes, and anticipated outcomes that will lead to systemic, integrated, and sustained family engagement across the state.

Table 1. KY Collaborative Activities, Short-Term Goals, and Systemic Goals.

\begin{tabular}{|c|c|c|c|}
\hline Activities & Short-Term Goals & $\begin{array}{l}\text { System-Wide Goals for Systemic, } \\
\text { Integrated, and Sustained } \\
\text { Family Engagement }\end{array}$ & Student-Level Goals \\
\hline 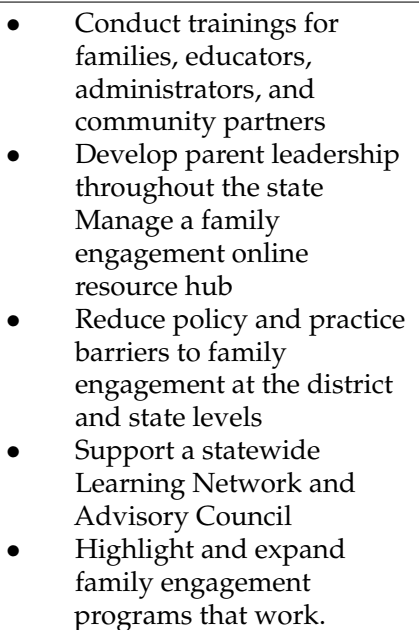 & $\begin{array}{l}\text { - Improved professional } \\
\text { practice: School and district } \\
\text { leaders invest in family } \\
\text { engagement and teachers } \\
\text { engage all families } \\
\text { as partners } \\
\text { Powerful parenting: Parents } \\
\text { are leaders and } \\
\text { decision-makers and are } \\
\text { aware of educational } \\
\text { options and resources } \\
\text { Public policy: Families and } \\
\text { educators hold leaders } \\
\text { accountable for } \\
\text { implementation of policies } \\
\text { that benefit families } \\
\text { and children }\end{array}$ & $\begin{array}{l}\text { - Schools where families are equal } \\
\text { partners in decision-making, } \\
\text { curriculum planning, policy and } \\
\text { resource development } \\
\text { Districts that allocate sufficient } \\
\text { funding toward family engagement, } \\
\text { implement a family engagement } \\
\text { policy, and share a core belief in the } \\
\text { value of engaging families } \\
\text { State Department of Education that } \\
\text { promotes and monitors existing } \\
\text { family engagement policies and } \\
\text { provides support and resources to } \\
\text { districts for implementation } \\
\text { Community partners that work in } \\
\text { partnership with schools and offer } \\
\text { high-quality services for all families, } \\
\text { and especially marginalized families }\end{array}$ & $\begin{array}{ll}\text { - } & \text { Ready for } \\
\text { kindergarten } \\
\text { - } \quad \begin{array}{l}\text { Improved 3rd } \\
\text { grade reading }\end{array} \\
\text { - } \quad \text { College and } \\
\text { career ready }\end{array}$ \\
\hline
\end{tabular}




\subsection{Collaborating for Transformational Family Engagement}

The beliefs, goals, and activities of the KY Collaborative are designed to accelerate transformational family engagement across the state. Warren and Mapp (2011) distinguish between transactional change, "the achievement of specific goals or objectives", and transformational change, "an internal change in how people or institutions act" (p. 228). Transformational family engagement strategies fundamentally change relationships between families and schools and interrupt deeply held beliefs about low-income, Black, Latinx, Indigenous, or immigrant families, each of which are rooted in systems of racism, classism, sexism, xenophobia, and their intersections.

As such, transformational family engagement must center communities, rather than schools, as schools have historically been oppressive spaces for many People of Color. The traditional school-centered model of family engagement is activity-based, treats parents as individuals, encourages parents to follow the school agenda, has workshops that provide information, and focuses on communication from the school to parents. In contrast, the ideal community-based model is relationship-based; emphasizes parents as members of a community, as leaders, and as collaborators in setting agenda; provides training for leadership development and personal growth; and emphasizes a mutual exchange of power (Warren et al. 2009).

The KY Collaborative offers a community-centered model of family engagement, but history cautions that community-based change often becomes an add-on to "business as usual" rather than integrating into school culture, practices, and policies. In the 1990s, community-based models, otherwise termed full-service community schools, school-linked services, wraparound services, or school-family-community partnerships, grew in popularity, leading to ample literature in that decade and the early 2000s highlighting their unfulfilled potential to yield integrated, systemic, and sustained change. Several comprehensive reviews have concluded that coalitions attempting to create change in schools did not accomplish their desired goals (Berkowitz 2001; Kadushin et al. 2005; Kubisch et al. 2010) due to power differences between community members and professionals; varying self-interests and organizational cultures that impede the development of a shared vision (i.e., "collabetition" (Ishimaru 2019)); failure to meaningfully engage those most closely affected (Chaskin 2001; Kubisch et al. 2010; Stone 2001; Tyack 1992); and tacking services onto existing practices, rather than altering social relations among teachers, students, administrators, and service providers (Smrekar and Mawhinney 1999; Tyack 1992; Wehlage et al. 1992). In his seminal book, "So Much Reform, So Little Change", Payne (2008), warns against "programitis", referring to the overemphasis on programs and services without attending to deep-seated mistrust in poor communities and schools that impedes program effectiveness. Mcknight (1995) contends that such arrangements may even be detrimental to poor communities, as professionals unintentionally "clientize" and disempower residents, minimizing their assets and focusing on the deficits that drive the need for social service work in the first place.

Additionally, scholars contend that community-driven, bottom-up approaches to change have been insufficient because they focus too narrowly on local issues and not enough on state and federal policy (Anyon 2005; Smrekar and Mawhinney 1999). While acknowledging the important ways local community-led initiatives have improved neighborhood conditions, Anyon also described how poverty rates did not change, and in many cases, increased, in communities with even the most celebrated paragons of bottom-up community development. The author detailed the macro-economic and political issues that extend beyond the control of even the most empowered localities, including low minimum wage, steadily declining incomes, limitations on union activity and membership, and a shifting jobs landscape that diminishes the worth of a high school diploma. These systemic barriers also impede civic participation itself. In the case of family engagement, poor access to transportation and internet, fear of deportation, community violence, and an economy that demands low-wage workers work multiple jobs, can all impede families' abilities to engage in leadership opportunities. 
In the second decade of the 21st century, collective impact became another popular approach to community and educational change, but one that has also received similar critique. Defined as "the commitment of a group of important actors from different sectors to a common agenda for solving a specific social problem at scale" (Kania and Kramer 2011), collective impact has five conditions, which include a common agenda, shared measurement, mutually reinforcing activities, continuous communication, and backbone support. In recent years, the collective impact model has received an increasing number of critiques for its lack of attention to equity and social justice. Ishimaru (2019) affirms how a collective impact model she studied had "little integration of systemic change efforts, educator capacity-building, and scaffolded parent leadership development strategies with one another or with core district priorities". The approach has also been critiqued for being too "grasstops"-led by professionals without meaningful engagement from those most closely affected (Christens and Inzeo 2015). Christens and Inzeo (2015) distinguish between collective impact and community organizing, in that the latter has deep resident engagement, closely analyzes power arrangements, and engages in conflict when necessary. The authors argue that collective impact and community organizing can complement and inform one another and assert a need for scholars to document and examine work at the intersection of these two approaches.

Despite these critiques, research illustrates that under the right conditions, collective impact can lead to systemic and population level change (ORS Impact 2018). One cross-site study of 25 collective impact initiatives in the U.S. and Canada found that such initiatives could lead to systemic and population level change when they take plenty of time to set the foundation for success (ORS Impact 2018). This includes defining the problem and the target population clearly, being sure to name communities with the greatest needs. Initiatives that spent the first couple of years strengthening the backbone organization and the common agenda were ultimately more effective. A strong backbone organization was one that focused on supporting others to lead change, rather than taking on the role of leading change themselves. Additionally, sites with the strongest common agendas often effectively engaged others, including policymakers and community members.

With racial equity and social justice at its center, the KY Collaborative offers a unique opportunity to address the successes and challenges of implementing an approach to transformative family engagement that is collaborative, community-based, and that fosters the organizational conditions that enable family engagement to be systemic, integrated, and sustained. As such, we present qualitative data to answer the following question:

How does a statewide family engagement center (the Kentucky Collaborative) offer a model for equitable collaboration toward transformational family engagement? What are its successes and challenges?

\section{Materials and Methods}

We used a case study design to analyze the successes and challenges of the KY Collaborative. A case study approach provides an in-depth examination into the day-to-day work of the partner organizations that contribute to the development of a collaborative, community-based, and equitable statewide model for transformational family engagement. Our data for this paper stem from a multiple year evaluation of the Kentucky Collaborative and is funded by the U.S. Department of Education statewide family engagement centers (SFEC) program. The multimillion-dollar grant was provided to the grantee, Prichard Committee, and partner organizations, Learning Grove, NCFL, Partners for Education and the Kentucky Department of Education, to promote and implement systemic evidenced-based family engagement strategies for the state of Kentucky. In the following sections, we detail the methods used during our initial year of documentation of the KY Collaborative. Note that the KY Collaborative was two years into their 5-year grant at the time of our data collection. 


\subsection{Sample and Recruitment}

A purposive sampling strategy was used to identify potential participants to be interviewed during this documentation. As one of the most popular forms of sampling in qualitative research, purposive sampling focuses on the richness a select group of participants can offer based on their lived experiences (Patton 1990). Using this technique, we identified key participants from the five partner organizations to interview based on the following criteria:

1. Must be a member of a KY Collaborative partner organization

2. Must be identified by SFEC grantee as key member of the KY Collaborative

3. Must attend weekly partner meetings or regularly engage/communicate with other KY Collaborative partner organizations

We sent partners who fit these criteria an invitation email to participate in an interview to share their collective experience leading family engagement services across the state of Kentucky. We limited our criteria to just KY Collaborative partners for this study as we wanted our analysis to reflect the experiences of partners as they built a model of family engagement to capture what they viewed as the successes and challenges of their work. We felt this was an important perspective to have for other states looking to model after this work.

\subsection{Data Collection}

We conducted in-depth interviews with $12 \mathrm{KY}$ Collaborative partners during the summer of 2020. Roles including directors and associate directors $(N=6)$, family engagement coordinators/specialists, and program coordinators $(\mathrm{N}=6)$. Each organization had $2-3$ representatives, but we do not link exact titles to organizations to protect their confidentiality. Table 2 shows exact titles.

Table 2. Titles of Participants.

\begin{tabular}{|c|c|}
\hline Role Type & Role in Organization \\
\hline Director level & $\begin{array}{ll}\text { 1. } & \text { Director of Programs } \\
\text { 2. } & \text { Senior Education Director } \\
\text { 3. } & \text { Senior Director-Leadership Development } \\
\text { 4. } & \text { Senior Director of Research to Practice } \\
\text { 5. } & \text { Family Engagement Director } \\
\text { 6. } & \text { Associate Director }\end{array}$ \\
\hline Coordinator/specialist level & $\begin{array}{ll}\text { 1. } & \text { Family Training Coordinator } \\
\text { 2. } & \text { Family Learning Specialist } \\
\text { 3. } & \text { Program Consultant of Early Learning } \\
\text { 4. } & \text { Family Engagement/Outreach Specialist } \\
\text { 5. } & \text { Family Engagement Coordinator } \\
\text { 6. } & \text { Exceptional Child Consultant }\end{array}$ \\
\hline
\end{tabular}

We established rapport with participants prior to scheduling and conducting interviews by spending time in virtual meetings with each partner organization. Using a topical interview protocol, we conducted semi-structured individual interviews via Zoom. Interviews were conversational in nature and guided by active listening and probing (Patton 1990). An example of key questions we asked during the interview include:

1. Can you describe the region you work in? What are the strengths and challenges?

2. How would you define family engagement? How would you define parent leadership?

3. In your opinion, what is the primary challenge for your schools and families around effective family engagement? How could the KY Collaborative help address this need? What policies and practices would help to decrease these barriers, either at the local or state level?

4. If you were to identify 2 or 3 things you think the KY Collaborative should focus on, what would they be? Why? 
5. Imagine its October 2023 and the grants are complete. If we did "it" successfullywhat would "it" look like?

Each interview lasted between 45 and $60 \mathrm{~min}$ and was audio-recorded. Extensive observational notes were also taken.

Other forms of data collection included observations of weekly partner meetings, monthly advisory council meetings, and SFEC evaluator meetings. An observation protocol was used to collect data in these meetings that assessed who was present, who spoke and when, what were the main points of conversation, and what were identified as key takeaways. Documents were also collected at each of these meetings (e.g., agendas, fliers distributed by hosts/participants, and any slides from presentations).

We also collected exit survey data $(\mathrm{N}=214)$ to explore the broader role of the KY Collaborative in strengthening family-school relationships through their statewide offering of programs and services at the conclusion of all KY Collaborative-sponsored activities. Seven activities are represented in these exit surveys, including advisory council meetings, monthly lunch-and-learns, parent cafes, groundswell gatherings, family engagement trainings, family engagement workshops, and the family leadership in education summit. We began documentation of these events in June 2020 and will continue until spring of 2023.

\subsection{Data Analysis}

Audio recordings were transcribed verbatim and checked for quality by the documentation team. All interview data were coded by multiple researchers. An emic coding method (e.g., focused on policies, practices, conditions, and beliefs of the collective KY Collaborative partners) (Lincoln and Guba 1985; Lincoln and Denzin 2003) was used to identify the themes and patterns within and across regional sites. Data analysis also entailed creating data displays (e.g., proximity matrices and descriptive data displays) and memoing, which assisted in the organization and comparison of partners' responses from the interviews. Specifically, proximity matrices were used to process, organize, and analyze the large amount of interview data across regional partners (Saldaña and Omasta 2016). The proximity matrices contained data about how alike and different partners' responses were (Bernard and Ryan 2010). Descriptive data displays were used to assist in the coding of KY Collaborative documents, publications, and observations to analyze descriptions, definitions, activities, people, and locations presented in printed materials and observed activities. Through the use of data displays, we were better able to identify patterns and themes, similarities, and differences, and make valid interpretations.

The most common codes applied during our analysis process were: covid transitions, challenge to family engagement, desire for KY Collaborative, alignment with the dualcapacity building framework, equity/social justice, family engagement, parent leadership, and sustainability. We then organized these themes into larger ideas that included: capacity building between schools and families, strengthening families through leadership and engagement, honoring families lived experiences, dual capacity building, connection building/resource support, racial equity, successes and challenges, and barriers to engagement and success. Our initial themes were then grouped into main themes around four central ideas, (1) how to build relationships and address historical barriers to family engagement, (2) key successes and challenges of building a Kentucky SFEC, (3) how the KY Collaborative is prioritizing the needs of Black, Latinx, Indigenous, and immigrant families, and (4) how the KY Collaborative is engaged in ongoing work to address racial equity and social justice in partnership with families and communities. We then used these main themes to construct our main findings for this paper.

\subsection{Managing Data Quality}

Through group coding meetings, we highlighted common policies, practices, conditions, and beliefs about family engagement guiding the collective impact of the KY Collaborative on Kentucky families, schools, and communities. This collaborative process aided in managing data quality and ensuring trustworthiness (e.g., the research is 
applicable in other settings, findings can be replicated, and descriptions of the participants, rather than the researcher are provided) was maintained. Qualitative data quality was maintained by including triangulation (e.g., the use of partner interviews, observational data, and KY Collaborative documents to examine ideas/concepts from participants in an effort to build coherent justification for study themes/findings), peer debriefing (i.e., research team meetings to probe about the methods, descriptions, conclusions, and possible biases that may be present in the study), member checking (i.e., ensuring data accuracy through reviewing and confirming data interpretations with partners), clarity in the data collection and analysis process, rich description in findings, and utilization of direct quotes (i.e., verbatim transcription of interviews with partners) (Lincoln and Guba 1985; Creswell 2013; Maxwell 2013).

Negative cases (e.g., contrasting evidence to the researcher's findings) and conformability (e.g., steps are taken to ensure that the findings result from the experiences and ideas of the participants and not the preferences of the researcher) ensure credibility of the qualitative data (Creswell 2013). We used negative cases throughout analysis to expand interpretations and understand our limitations. Negative cases were compared to our main findings to see alignment and disagreement and to outline the factors that contribute to their differences. For example, some partners reported challenges engaging with emergent bilingual families while others did not. In these situations, we analyzed how regional differences and community demographics shaped perspectives to account for negative cases.

\section{Results}

Key findings presented in this section emerged from our analysis of individual interviews, observational data, and some survey data collected from members of partner organizations in the KY Collaborative. Findings are presented thematically in four sections, highlighting the ways in which the KY Collaborative is strengthening family-school relationships through their statewide offering of programs and services.

\subsection{Breaking through Historical Barriers}

Research has shown the importance of family-school partnerships to the success of children (Ishimaru 2019; Mapp and Bergman 2019; Ishimaru and Takahashi 2017). The KY Collaborative has prioritized the development of engaged families and parent leaders through the offering of place-based and virtual programs and services offered across the state of Kentucky. Partners believed that this was crucial to breaking through historical barriers (e.g., teachers' lack of cultural competency, traditional modes of engaging families in schools that often exclude families' voices and assets, as well as limited resources and supports for allowing families to feel supported and welcomed in their child's school) that fail to acknowledge the critical role families play both within and outside of schools.

The first key way in which the KY Collaborative is breaking historical barriers is by providing leadership opportunities for parents. The Commonwealth Institute for Parent Leadership (CIPL) has a continuum of engagement and leadership opportunities with a focus on dual-capacity building "for families, schools and communities to increase academic success of Kentucky students and progress of Kentucky's public schools". Through this program, participants are able to "connect with others that share their determination and experience; brainstorm ideas about their local work; share valuable connections and resources; and build strong peer-to-peer relationships that are relied upon for support and ideas", through the offering of "webinars, networking opportunities, community leadership, statewide events, and local projects".

As highlighted by partners, programs like CIPL are crucial to "strengthening families. It's making the invisible visible and the visible more intentional", by ensuring that "families are always invited to the table".

But families need more than an invitation to the table, and the KY Collaborative works to ensure families have the tools and resources to not only be an engaged parent, but also an effective parent leader. One partner described: 
I equate [parent leadership] to 'what the world would be like if when every kid turned 16 we just handed them car keys and said go drive?' [If] you don't teach them the rules of the road, teach them laws, [they can] get in severe trouble... We kind of do the same thing to parents. We say, 'okay, drop your kid off at the school door when they're five and see you later'. We don't teach them what's going to happen to their kid all these years that they're in the school building and how to positively interact [with the school] for the benefit of their child and other children in their neighborhood.

The KY Collaborative, as described by another partner, "is really good at not only just informing parents and listening to parents, but actually providing leadership opportunities" through various initiatives. One such partnership between partner organization NCFL and a local community organization is supporting parents/caregivers in collaboration with program staff and community leaders to develop a district wide toolkit for equitable family engagement. Through a series of workshops, families and community members came together to discuss what they believed were historical and systemic barriers to learning for students who identify as Black, Indigenous, or other People of Color. (BIPOC). Together, they co-constructed guiding practices they believed would increase students' academic and socioemotional development, including prioritizing parent voice in schoolbased programming and decision-making processes, creating guiding modules for teachertraining about racial equity, and addressing local curricula to ensure it is responsive and sustaining to students and their families.

The second way the KY Collaborative is breaking through historical barriers is by increasing professional learning opportunities for educators, leading schools to honor and acknowledge families' lived experiences. One partner asserted:

Educators don't get any formal training on family engagement... we're basically seeing people go into higher education who want to become educators. They get a teaching certificate and there's not one course designed to help them understand the people that they're going to be engaging with.

When educators lack the formal training to engage with families in meaningful and authentic ways, the unique assets, voice, and lived experiences of students and their families are missing from the school. However, partners reiterated that "true partnership is what we're working towards". Therefore, while educators may be "doing their job the best way they know how based on what they've been given", the KY Collaborative is working to shift the "culture of education" from letting the school administration establish the policies and practices to building meaningful partnerships between families and schools in order to work through some of those barriers.

One way that this is taking place is through the development of a network of 52 partner schools across the state of Kentucky that receive high-impact programs and services from KY Collaborative partner organizations. The KY Collaborative confirmed that the development of a network of partner schools creates a learning community across the state of Kentucky that is "focused on increasing open communication, learning opportunities and shared decision-making power across the Kentucky education system". At the core of this initiative is the belief that "high-quality, equitable and inclusive education is the shared responsibility of families, schools and communities". KY Collaborative partners believed success meant families "truly feel[ing] like a partner in [their] child's school ..." and ensuring that families believed they were both "valued" and "welcomed" in supporting their child's learning. It is important to note that partners created this network halfway through the grant, after they took ample time to learn about the dual capacity-building framework and reflect together on how to integrate their work into the fabric of schools, unlike prior family engagement initiatives that had been an add-on to business-as-usual.

The third way the KY Collaborative is breaking through historical barriers is by defining and focusing on high-impact family engagement services and programs, rather than isolated events and trainings. Through a long process of dialogue and revision, 
as well as support from the evaluation team, the KY Collaborative created a definition of high-impact programs and services that must include the following 6 elements:

1. There is evidence this activity meets an identified need for our target population and local needs. We can validate the need for this activity based on assessment, survey or other local data.

2. This activity supports our shared goal to increase students' and/or adults' learning and development.

3. This activity is research-informed by literature that focus on the experiences, stories, and lived experiences of targeted demographics, is evidence-based, or has a process for continuous improvement.

4. There are opportunities for parent leadership and parent partnership within this activity.

5. There are opportunities for two-way engagement.

6. There are considerations in the design of this activity for how it can be systemic, integrated, and sustained within schools, districts, or organizations

These criteria have informed new programs and services and have pushed partners to reconsider some of the existing services they offer. By aligning programs and services across the state with these principles, partners can still be responsive to their unique contexts while also diffusing transformational family engagement practices statewide.

Initiatives such as CIPL, the network of 50 partner schools, and high-impact family engagement programming demonstrate the KY Collaborative's commitment to strengthening families, building capacity amongst schools and educators, and supporting communities to achieve educational equity.

\subsection{Collective Experience to Tackle Challenges}

Each of the KY Collaborative partner organizations has its own set of assets and experience navigating their region of Kentucky. Thus, partners highlighted their "collective experience of cradle to career orientation", as a leading success and strength of the collaborative. Table 3 illustrates the region, key services, and target demographic for each of the partners.

One partner shared the "strength that we have with the grant is that we have three partners who are on the grant with us, who represent [all the regions]". While each region and partner organization may face unique challenges (e.g., accessibility, transportation, language barriers, and high rates of poverty), statewide collaboration has provided resources and insights into how to best reach families in adaptable ways, especially during shifts in programs and services during forced remote programming due to the global pandemic. For example, CIPL was able to enroll more emergent bilingual families (formally identified as English Language Learners) in their parent leadership workshop due to regional support from a partner organization, Learning Grove.

Additionally, the KY Collaborative collectively organized a Family Leadership in Education Summit, where they tapped into each of their networks to deliver multi-day presentations and interactive webinars around transformative family engagement. Centered around engaging educators, parents, students, and community-based organizations, partners sought to engage in dual-capacity building, where participants could learn to "recognize that high-quality, equitable, and inclusive education is the shared responsibility of families, schools, and communities".

One partner shared that the collective community-based model of the KY Collaborative is important as "we now have more families who have never been part of their kids' school intentionally" engaged as parent leaders. Some of these families have faced racialized discrimination, intimidation because of language barriers, or lack of access due to transportation costs who now feel "empowered" with the needed tools to advocate on behalf of their children in schools and their communities. When the partner organizations are able to learn from and with each other, increase each other's community reach, and support more opportunities for dual-capacity building statewide, both families and schools benefit. 
Partners are using their networks to work across regions and ensure they are "making opportunities [for families] to be a part of the overall engagement strategy for the schools" by ensuring schools understand that "family engagement is an asset-based resource that schools can have to improve the outcomes of their students" via workshops, training, and on-going community conversations. For example, the KY Collaborative launched a Family Engagement for Educators Toolkit, with 6 content items to prepare for teachers to engage with families in meaningful ways. Educators watch interactive videos, engage in reflective questions, and learn key terminology and practices for transformative family engagement. On the KY Collaborative website where the toolkit can be accessed, educators, families, community members/organizations are also able to access shared resources and guides on family engagement.

Table 3. Description of Regional Partners.

\begin{tabular}{llll}
\hline \multicolumn{1}{c}{ Organization } & \multicolumn{1}{c}{ Region/Population } & \multicolumn{1}{c}{ Key Services } & \multicolumn{1}{c}{ Target Demographic } \\
\hline Learning Grove & $\begin{array}{l}\text { Northern } \\
\text { Kentucky/Emergent } \\
\text { Bilingual Families }\end{array}$ & $\begin{array}{l}\text { Early care and education centers, before-and-after } \\
\text { school programs, college and career prep, parent } \\
\text { leadership and resource support }\end{array}$ & $\begin{array}{l}\text { Early childhood (aged 0-5), } \\
\text { school-aged children, and } \\
\text { parents/caregivers }\end{array}$ \\
\hline $\begin{array}{l}\text { Kentucky } \begin{array}{l}\text { Department of } \\
\text { Education }\end{array} \\
\text { Statewide }\end{array}$ & $\begin{array}{l}\text { Policy lever; administrative agency providing } \\
\text { leadership, service, and support to school districts via } \\
\text { policy governance; key role in the KY Collaborative is } \\
\text { to listen and learn how policies can be informed } \\
\text { by families }\end{array}$ & All ages \\
\hline $\begin{array}{l}\text { Fational Center for } \\
\text { Families Learning }\end{array}$ & $\begin{array}{l}\text { Louisville/Southeastern } \\
\text { Region/Urban Families }\end{array}$ & $\begin{array}{l}\text { Place-based family literacy, learning and engagement } \\
\text { programming, professional development to support } \\
\text { family learning and literacy practitioners, and } \\
\text { community development to highlight local voices }\end{array}$ & $\begin{array}{l}\text { Early childhood (aged 0-5), } \\
\text { school-aged children, adults, and } \\
\text { parents/caregivers }\end{array}$ \\
\hline Education & Appalachian Region/ & $\begin{array}{l}\text { College preparation, academic skill building, college } \\
\text { and career mentoring, and family } \\
\text { engagement programming }\end{array}$ & $\begin{array}{l}\text { Early childhood (aged 0-5), } \\
\text { school-aged children and } \\
\text { parents/caregivers }\end{array}$ \\
\hline Rural Families & Statewide & $\begin{array}{l}\text { Community based advocacy networks, trainings, } \\
\text { leadership institutes, and post-secondary attainment } \\
\text { and career readiness }\end{array}$ & $\begin{array}{l}\text { Early childhood (aged 0-5), } \\
\text { school-aged children, adults, and } \\
\text { parents/caregivers }\end{array}$ \\
\hline
\end{tabular}

The partners shared the importance of "statewide accountability" in regard to family engagement and why the Kentucky Department of Education plays such a crucial role in the KY Collaborative. Some believed that the KDE added a way to "push for support around [prioritizing family engagement] in some way that has teeth". For many of the partners, there is hope that by the end of 2023, their collective approach would result in "a uniform system for family engagement supported by KDE (Kentucky Department of Education)". In this system, there would be guiding norms, policies, and practices for engaging families across the state of Kentucky that would be "backed and supported by $\mathrm{KDE}^{\prime \prime}$. Although representatives from the KDE attend the weekly partner meetings and have been strong supporters of the Collaborative, the Department's role in systematizing family engagement throughout the state is a work in progress.

The KY Collaborative understands that shifting the culture around family engagement in Kentucky requires a "reach to each" approach, which is supported by the unique framing each partner organization brings to the table.

\subsection{Family-Driven Services That Uplift Racial Equity and Social Justice}

Historically marginalized families continue to face various barriers to feeling welcomed and valued as engaged members of their school community. Their voices are often silenced and their lived experiences ignored. The KY Collaborative is working to uplift the voices of these families in order to develop opportunities for them to be active decision makers and co-creators in their child's learning experience. One partner affirmed that, "even though we've had 40 years of forced busing [and] and some neighborhood 
integration, [Kentucky is] still very segregated". Therefore, some of the work from the KY Collaborative must be around shifting mindsets.

Educators often use students' racial/ethnic background, neighborhood of residence, and parents' level of involvement in the school to make assumptions about a student's potential for academic success. Partners highlighted systemic and institutional policies and practices, such as tracking and ability testing, that are used in some schools to keep students from being placed in what teachers believe are classes outside of their scope of ability. One partner confirmed:

Kids that I've mentored over the years that are qualified for the advanced program with testing aren't placed in the advanced program because the teacher doesn't recommend that they be in the advanced program. They think the family can't support that level of work that the kids can be asked to do.

Other partners have stated, "there's a lot of history we're fighting". This is due to "racial bias that exists, and the judgments that are made". Some partners believed that "based on race and based on economic ability of the family, they aren't valued ... We're trying to create space for them to be valued and again give them the background information that they need to participate at a higher level".

Language is also a barrier for families to be supported in schooling spaces. Creating an environment where parents/caregivers feel valued and respected is critical for equitable partnerships to be formed. However, in some situations, partners discussed the lack of resources that were available for all families to engage in school-related activities. One partner described:

Our Hispanic population is so small. They were very low on the radar. The Hispanic families are not even considered. So, it's a language barrier at the school where teachers would invite the families. English speaking families [would be] on one side and Spanish [speaking] families on the other side.

Shifting mindsets around which parents' voices should be valued would create new opportunities for all families to be authentically included. For example, when preparing documents to be sent home to families, or hosting events where families will be present, making it a standard practice that translations are always available.

Advocacy is needed around racial equity and social justice and some partners believe it is their responsibility to break down these barriers. One partner asserted:

To name, address, confront and help families with overcoming the challenges of systemic racism ... I think it's our agencies' responsibility. The opportunity to have this grant to create opportunities for families to be successful and help their children be successful in school and beyond.

In order to aid in shifting mindsets about the assets and possibilities BIPOC families can offer to support their child's learning both within and outside of schools, the KY Collaborative offered dual-capacity services that are offered through the KY Collaborative to address these challenges from multiple angles. For example, one partner believed getting teachers "to see family engagement as an asset to what [they're] doing, instead of something else that [they] have to do", is critical to ensuring that historically marginalized populations feel welcomed, supported, and valued in their child's school. The KY Collaborative tackled this in their "Top 10 Family Engagement Projects for 2020", which included, "creating family-friendly classroom and school certifications, building 8 online family engagement trainings and resource toolboxes, increasing family engagement curriculum in college courses and teacher certifications, and designing an online family engagement resource hub with interactive guide of educational options".

Exit survey data from teachers, counselors, principals, district staff, and parents/ caregivers who participated in KY Collaborative services (e.g., advisory council, monthly lunch-and-learn, family engagement training/workshop, parent café, groundswell gathering, or family leadership in education summit) from 2020-2021 support qualitative claims of dual-capacity building via engagement in a KY Collaborative event, workshop, or activ- 
ity. Of overall respondents, $92.92 \%(\mathrm{~N}=214)$ reported they learned something that will help them engage in better family engagement practices (see Figure 1).

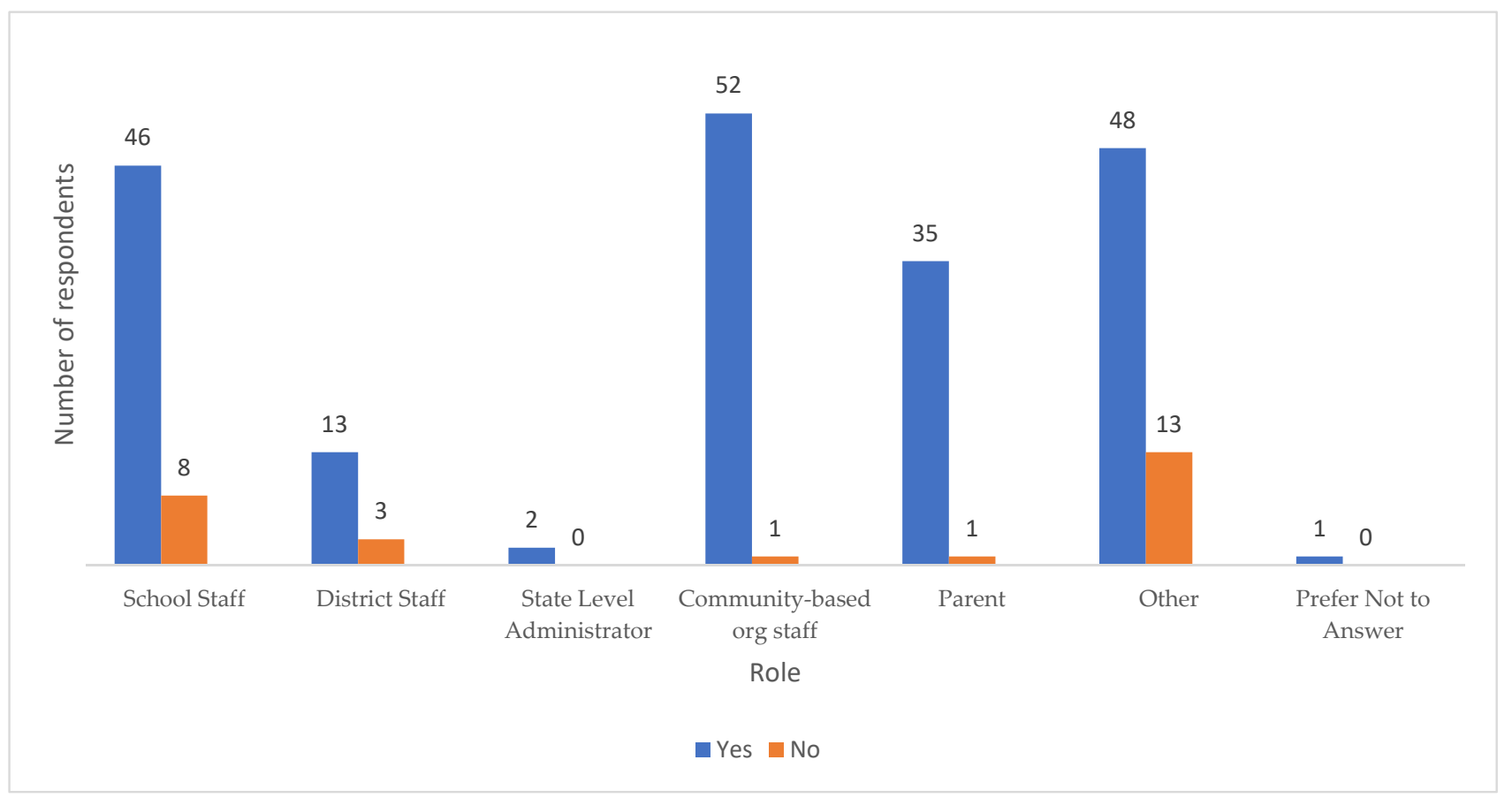

Figure 1. Respondents reporting learning new family engagement tools.

When asked if they became more aware of educational programs, services, or resources to support student learning through engagement in a KY Collaborative activity, $80.75 \%$ of overall respondents $(\mathrm{N}=214)$ reported yes (see Figure 2$)$.

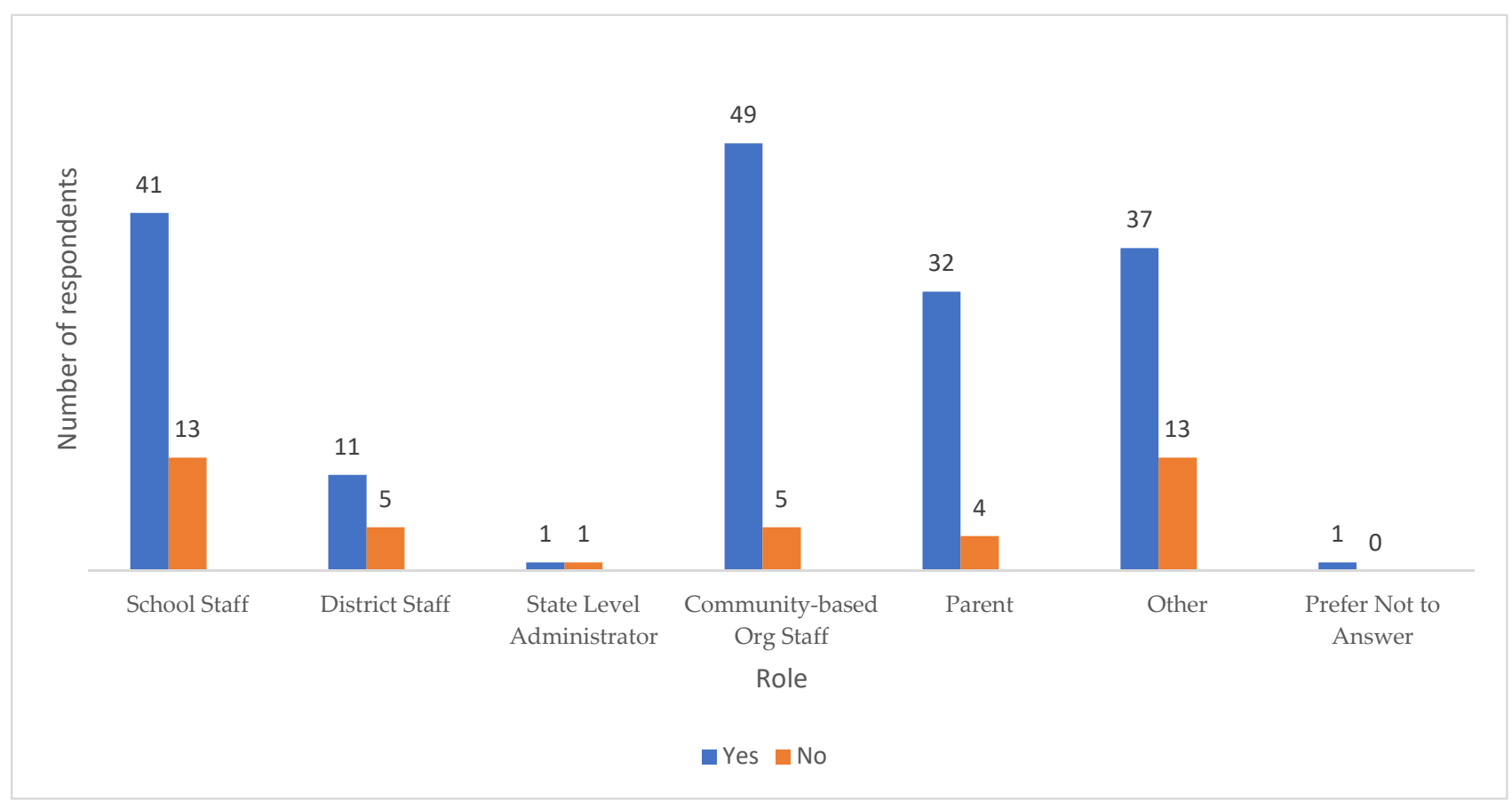

Figure 2. Respondents reporting increased awareness of family engagement services. 
One partner believed that building dual capacity in parents meant ensuring their access to resources to become informed leaders. They confirmed:

I think part of it is being able to make sure that information is available through multiple channels in multiple languages. That we really give parents the tools that they need to advocate for their own child in their own communities. So they hold the power. What we feel like our role is, is to work on the ground to help them realize that power and be able to move forward to make real change in their schools.

In this approach, the KY Collaborative is "making sure that parents understand the system their child is engaged in", "helping parents find their strength", and "meeting each family where they're at" while simultaneously building skills and capacity in educators to build the foundation for "families and schools to work together".

\subsection{Ongoing Work to Deepen Racial Equity and Social Justice}

The social and political context of 2020, including a global pandemic as a result of SARS-CoV-2 (also known as COVID-19) and racial uprisings around the murders of George Floyd, Breonna Taylor, Ahmuad Arbry, and many others, has caused many organizations to consider how to strengthen their racial equity and social justice-centered work. The work of the KY Collaborative was directly impacted by the death of Breonna Taylor, which occurred in Louisville, the biggest school district in Kentucky. One partner described this tragedy as a "pivotal point in our work as a collaborative", as it forced many difficult conversations about race and racial tensions in Kentucky.

As evaluators on this grant, we felt an obligation to embed culturally responsive and sustaining family-engagement practices into our documentation, ensuring that partners had the space to reflect on the ways in which they could deepen their focus on racial equity and social justice. We co-created a guiding definition of culturally responsive and sustaining family engagement in collaboration with KY Collaborative partners and advisory board members. This process consisted of (1) identifying what we (evaluators, partner organizations, and advisory council members) believed were key priorities of the KY Collaborative, (2) referring to existing literature on definitions of family engagement (e.g., Ishimaru 2019, 2020; McWayne et al. 2019; Henderson et al. 2007) to identify areas of improvement in the existing version, (3) drafted a re-imagined definition of family engagement, then (4) shared with all partner organization and advisory council members for approval. This process of revision required a lot of deep listening to one another and pushing back in some instances when needing to be explicit about race/naming racism (e.g., identifying a key priority of the KY Collaborative as being anti-racist and not just anti-discriminatory). Our re-imagined definition of culturally responsive and sustaining family engagement stated:

Culturally Responsive and Sustaining Family Engagement focuses on families and schools working in partnership to develop programs, policies, and practices that empower students' learning. Families and schools are equal partners in decision making, curriculum planning, policy and resource development, amongst other things. The goal is to establish a trusting/authentic relationship, where parents are viewed as the experts on their and their children's lived experiences and needs. In this form of engagement, outreach to families should be active and personal as much as possible.

We also worked together using the same process outlined above to re-imagine how parent involvement and parent leadership should be defined. We understood these as:

Involvement is families gaining resources/tools or learning information but not having to engage in a two-way conversation with school and/or child. (Examples: Social media hits, receiving a book in the mail, newsletters, orientation night for all families, interest surveys sent home). 
Leadership includes both public and at-home practices. Public leadership is creating space for parents to authentically lead and empowering families with resources, networks, and information to lead in school, community, and other public spaces. At-home leadership is supporting families with resources, networks, and information to continue to support their child's learning and development, including acknowledging and honoring families' private practices to ensure their children's educational futures.

It was important to re-define these terms to prioritize families as equal partners in their child's schooling, understanding their cultural nuances, and recognizing the assets they bring as experts on their child's needs and abilities. These definitions also allowed us to categorize programs and services offered across the KY Collaborative and re-center ways to engage families and schools in meaningful and authentic ways.

Key programs and resources addressing racial equity and social justice emerged over the last 12 months of observing KY Collaborative services. For example, KY Collaborative partners have organized courageous conversations/learning circles with families, educators, and community members in order to have deep conversations about race and parents' racialized experiences in their schools as well as during programs and services.

One partner described what she felt was a responsibility to have conversations about race during Parent Cafes. This partner affirmed a need for individuals to be accountable for their words and actions and just be "more culturally aware". Therefore, working to "reframe conversations [in order to] open up those lines of communication". When individuals, particularly historically marginalized folks, feel their lived experiences, identities, and needs will be valued and heard, they are more likely to engage, allowing meaningful and authentic partnerships to be developed (Ladson-Billings 1995; Paris 2012; Mapp and Bergman 2021).

KY Collaborative partners believed that "real, sustainable change happens locallyone child, one family, one neighborhood, [and] one community at a time". A KY Collaborative initiative we observed that uplifts this principle is the Groundswell Initiative. Guided by what one KY Collaborative partner described as a "reach to each" philosophy, the Groundswell Initiative "is all about communities responding to the unique needs of students and families locally, to realize better outcomes in education-early childhood through postsecondary". Individuals are able to register to be Groundswell members, where they're committed to be the "boots on the ground" and advocate for local community change to improve education for all students. For example, in Jefferson County, Groundswell members created a program called YES4JCPS, where "a group supported a ballot measure that would improve education outcomes with a focus on racial equity in Kentucky's largest school district".

Other ways the KY Collaborative continues to center racial equity and social justice in their day-to-day work includes updating public facing documents with language that affirms their stance on prioritizing race, ethnicity, language, SES, and gender parity. For example, the KY Collaborative one-pager shared with schools, families, and community partners asserted they are "committed to equity" by:

Supporting effective strategies to remove all barriers to educational equity, including systemic racism. Through open and honest conversations and actions around racial disparities, belonging, and equity in our schools, we support students and to achieve their dreams for themselves and our Commonwealth.

While there is still work to be done, the KY Collaborative has begun to demonstrate that racial equity and social justice are priorities. They are working together with families and schools to facilitate necessary conversations about what it means to be anti-racist and anti-discriminatory, how to honor families' lived experiences, and develop true partnership. Over the next two years, the KY Collaborative partners hope to "see a lot more equity in our school districts", improved "partnerships between all the school districts and families", and an understanding that "we're in this together". 


\section{Discussion}

This paper aimed to explore how the collective impact model of the KY Collaborative promotes and implements systemic evidenced-based family engagement strategies for the state of Kentucky. Qualitative methods, including first-hand accounts from KY Collaborative partners, observations of KY Collaborative events, and analysis of KY Collaborative documents, produced rich data detailing the policies, practices, norms and services shifting mindsets around family engagement in Kentucky schools and communities. This work provides clear insights into the significance of equitable collaborations for transformational family engagement. Specifically, findings highlight the ways in which low-income families and families of color are best supported when mindset shifts around school-family partnerships take place in a culturally responsive and sustaining way.

The KY Collaborative began their collective work to develop a statewide model for transformational family engagement in 2019. For the last two years, the partners have worked together to develop a collective vision for what this process of transformation would entail. A key priority for partners was the sustainability of their work and they have addressed this by ensuring dual-capacity building for both families and educators. Partner alignment around shared vision and goals is a testament to the importance of regular communication (e.g., weekly team meetings) and taking a lot of time to set a vision and mutual agenda (ORS Impact 2018). For the KY Collaborative members, this is an ongoing process and their vision for the work continues to evolve as it grows.

As highlighted in Figure 3, four key themes emerged from our data. The KY Collaborative intentionally addressed historical barriers to family engagement, used their collective experience and expertise to tackle challenges, prioritized family-driven services that uplift racial equity and social justice, and committed to ongoing work to deepen racial equity and social justice.

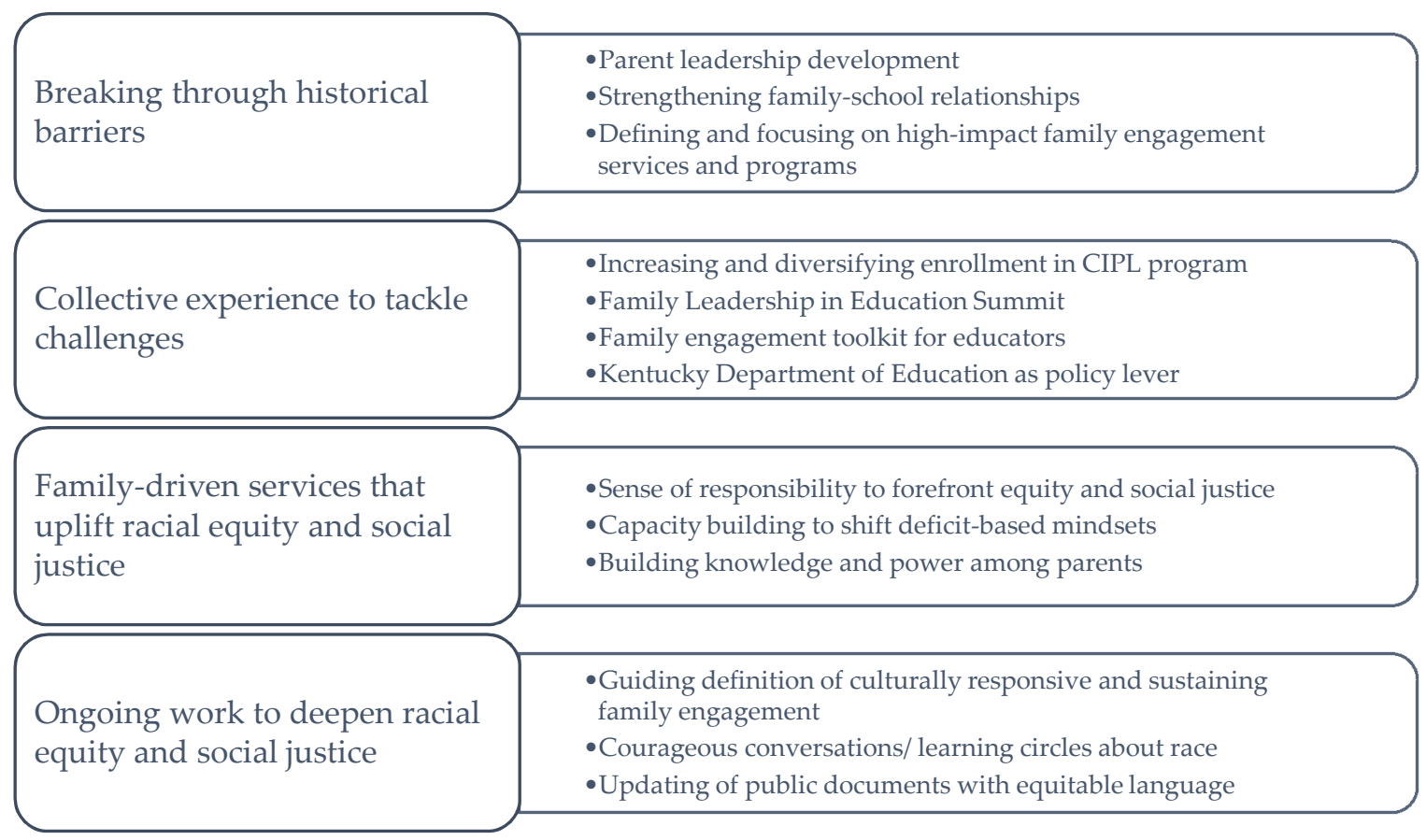

Figure 3. Main themes from KY Collaborative data.

For partners, transformational family engagement begins with families. In order to strengthen family-school relationships through their statewide offering of programs and services, the KY Collaborative needed to first focus on breaking through historical barriers and interrupt deeply held beliefs about low-income families, Black, Latinx, Indigenous families, and immigrant families that often exist in schools. These ideals, which are 
rooted in systems of racism, classism, sexism, xenophobia, and their intersections, many times make BIPOC families and students feel they are not welcomed or valued as assets or experts on their academic, social, and emotional needs and possibilities. Through programs like CIPL, where parents develop skills to be active parent leaders in their schools and communities, or through NCFL partnerships with community organizations to develop racial equity toolkits to inform local school policies, parents learned effective leadership and advocacy skills. Simultaneously, teacher training programs, family-friendly classrooms and school certifications, online family engagement trainings and resource toolboxes, family engagement curricula in college course offerings and teacher certifications, and an online family engagement resource hub with interactive guides for educational options taught educators the value of listening and partnering with families to best support their students.

Ensuring KY Collaborative programs and services were meaningful and aligned with the needs of all Kentuckians, the KY Collaborative partners needed to leverage each other's strengths. Each organization has long-lasting relationships built in their regions, where they have partnered with local school districts, community organizations, parent leaders, students, and their families. Partners have used these relationships to build statewide resources, such as the family-friendly network of schools. Now, 52 schools across the state of Kentucky can work in partnership, co-create, and learn from each other. Relationships such as these, and the learned lessons that come from them, are critical, especially now, as schools move back to in-person learning after a year of COVID-19 transitions.

Racial equity and social justice were identified as key priorities of the KY Collaborative over the last year. Locally, many students and their families felt directly impacted by the death of Breonna Taylor. Many partners believed it was important to begin transforming their work to have more intentional conversations about becoming anti-racist and antidiscriminatory. In an effort to deepen their racial equity work, partners have facilitated sometimes uncomfortable conversations via parent cafes, courageous conversations, and monthly lunch-and-learns. Public facing documents, with the support and approval from advisory council members, outlined guiding definitions around what culturally responsive and sustaining family engagement would look like, directly and specifically outlining the need to honor the lived experiences of BIPOC families.

\subsection{Implications: Toward Next-Generation Family Engagement}

Several decades of research show common pitfalls of not grounding family engagement and community-based change in equity and social justice frameworks. Wolfe et al. (2020) identified six principles for collaborating for equity and justice in response to the varied critiques of collective impact models: (1) explicitly address issues of social and economic injustice and structural racism; (2) develop community members' capacity to have equal power in determining the collaborative's agenda and resource allocation; (3) employ community organizing as an intentional part of the process, including power mapping and confronting conflict; (4) focus on policy, systems, and structural change; (5) build on community-engaged scholarship that shows what works; and (6) build member ownership and leadership beyond the backbone organization. Weiss et al. (2018) identified five areas for "next generation" family engagement: (1) learning from the innovative practices families and communities are already engaging in and supporting them to continue; (2) capacity building and professional development, including shifting mindsets about "good" family engagement; (3) supporting families to use data to make decisions and hold schools accountable; (4) building policymaker interest and commitment to family and community engagement; and (5) generating public interest in and excitement about family and community engagement through public communication.

The five "next-generation family engagement" strategies and the six principles for collaborating for equity and social justice overlap considerably. Both models allow us to more deeply consider how change can be driven by those who have the most to lose or gain; how systems, structures, policies, and mindsets need to shift to accomplish change; and how leadership may be diffused across a system rather than concentrated with a 
single entity. Drawing from both of these models, our findings suggest that equitable collaborations for transformational family engagement must attend to five components:

(1) Bottom-up leadership: Families and communities have a voice at every level-the collaborative itself, districts, schools, and community-based organizations

(2) Dual-capacity building: Families, teachers, school leaders, and service providers receive ample support for sharing power

(3) Shifting power: Families, especially those who have been most marginalized, drive the agenda and hold education officials accountable

(4) Changing policy: Develop public will for family engagement in order to create policies that facilitate family engagement and leadership and undo policies that impede it.

(5) Diffusion: Putting forth unified narratives about the power of transformational family engagement that are shared across a system

Table 4 displays how components of these three models relate to one another.

Table 4. Components of equitable collaborations for transformational family engagement and related components from models of "Collaborating for Equity and Social Justice" and "Next-Generation Family Engagement".

\section{Components of Equitable \\ Collaborations for Transformational \\ Family Engagement}

Bottom-Up Leadership: Families and communities have a voice at every level-the collaborative itself, districts, schools, and community-based organizations

Dual-capacity Building: Families, teachers, school leaders, and service providers receive ample support for sharing power

Shifting Power: Families, especially those who have been most marginalized, drive the agenda and hold education officials accountable

Changing Policy: Develop public will for family engagement in order to create policies that facilitate family engagement and leadership and undo policies that impede it.

Diffusion: Putting forth unified narratives about the power of transformational family engagement that are shared across a system

$\begin{array}{ll}\begin{array}{l}\text { Related Components of Collaborating } \\ \text { for Equity and Social Justice } \\ \text { (Wolfe et al. 2020) }\end{array} & \begin{array}{l}\text { Related Components of } \\ \text { Next-Generation Family }\end{array} \\ & \text { Engagement (Weiss et al. 2018) }\end{array}$

Build member ownership and leadership Learning from the innovative practices beyond the backbone organization families and communities are already engaging in and supporting them to continue

Develop community members' capacity to have equal power in determining the collaborative's agenda and resource allocation

Explicitly address issues of social and economic injustice and structural racism Employ community organizing as an intentional part of the process, including power mapping and confronting conflict

Focus on policy, systems, and structural change
Capacity building and professional development, including shifting mindsets about "good" family engagement

Supporting families to use data to make decisions and hold schools accountable; Building policymaker interest and
commitment to family and community engagement
Build on community-engaged scholarship that shows what works
Generating public interest in and excitement about family and community engagement through public communication

First, in regard to "bottom-up leadership", the model that includes regional partners who are deeply embedded within communities positions those partners to learn from what is working and share these practices statewide. This contrasts with top-down approaches, such as implementing an evidence-based program in a community without attention to local buy-in and fit (Geller 2016). As stated, some examples of this include the KY Collaborative's motto of "a reach to each", partnerships with local place-based programs through initiatives like Groundswell, as well as collaborations with local school districts to develop policies, equity toolkits, and leadership programs. As Ishimaru (2020) states, collective impact models for family engagement should combine "the experience of educators and policymakers" with the "brilliance of young people and their families and communities" (p. 34). 
Second, regarding "dual-capacity building", the KY Collaborative recognizes that dual capacity has to be developed so that both families and educators are prepared to come together in true partnership to put student learning first (Mapp and Bergman 2019). Dual-capacity family engagement training helps teachers to understand that family engagement is not a liability or another thing that they need to check off of their list of to-do's. Rather, the KY Collaborative is working to train teachers to see the asset in partnering with families. What true partnership and family engagement does is create shared responsibility for students ${ }^{\prime}$ outcomes. While this promotes success for all students, it is especially important to ensure that low-income students and students of color (e.g., Black, Latinx, Indigenous families, and immigrant families) are learning in environments that are culturally responsive and sustaining. The KY Collaborative's approach to dual-capacity family engagement and parent leadership training has been via a community-based model that truly focuses on building relationships with not only families but also educators. By creating a family friendly school network across the state of Kentucky, they are delivering a clear and concise message to all regions that family engagement matters and more specifically the way that family engagement is acted upon matters.

Third, regarding "shifting power", educational equity must be rooted in culturally responsive and sustaining practices, and families must be part of equity initiatives (Moll et al. 1992; Mapp and Bergman 2021). Parents/caregivers are the experts on their children's lives, needs, desires, assets, and future possibilities. Student success cannot be achieved in a meaningful way without including the voice of their families. Through the KY Collaborative, the Prichard Committee has expanded CIPL programming across the three SFEC regions, reaching a sizable emergent bilingual population for the first time. The KY Collaborative is pushing for a transformative family engagement model, where families and schools are equal partners in decision making, curriculum planning, and policy and resource development. Through this work, the goal is to establish trusting and authentic relationships, where families are viewed as the experts on their family's lived experiences. As highlighted by the partners and in relevant literature, racism continues to be a barrier to learning for students of color. Transformative family engagement can help shift these mindsets.

Fourth, the KY Collaborative is attentive to "changing policy". Unlike top-down advocacy organizations, CIPL has built a bottom-up movement over the years. There is ample potential for CIPL Fellows-supported and bolstered by other systems leaders throughout the Commonwealth who are being impacted by the KY Collaborative-to enact policy change and hold schools and districts accountable for implementing existing family engagement laws that are currently not enforced nor supported. The theory of change behind CIPL has always been that effective and sustained policy implementation to improve Kentucky's schools requires informed and skilled parents (Kroll et al. 2001). Furthermore, the KY Collaborative is positioned to attend to policy by engaging the Kentucky State Department of Education as a partner. Although a work in progress, the KY Collaborative is working to see family engagement integrated into the everyday functioning of school systems.

Fifth, through a diffused leadership approach, the goal is that all partners will amplify a common message and vision for family engagement throughout the state. For example, the statewide "Family-Friendly School Cohort" brings together schools to develop a common understanding of equitable family engagement and promote cross-school learning. All of the KY Collaborative partners have a shared idea about family engagement which is evidenced by the steps taken to co-create guiding definitions (e.g., family engagement, parent involvement, parent leadership, and decision-making) as well as outlining clear activities that will be implemented across the state in each of the regions where partners operate their own programs and services. The partners worked together to create shared measures in determining the impact of their programs and services across the state of Kentucky, making clear the priority of high-level engagement in order to be characterized as a high-impact service. 
One contribution of this paper is putting forth a framework for understanding how to merge what researchers have identified as key future directions for transformational family engagement (Weiss et al. 2018) and equitable and justice-oriented collaborations (Wolfe et al. 2020). The framework of (1) bottom-up leadership, (2) capacity building, (3) power, (4) policy, and (5) diffusion can be used by other Statewide Family Engagement Centers and similar initiatives, especially those that are in the early phases of designing their approach. The framework can also be further tested and refined through future research. For example, future research could further illuminate successful practices in each component and examine how they reinforce one another, as well as how the components yield organizational conditions for home-school partnership

\subsection{Limitations}

The data presented in this study represent one year of documentation of the Kentucky SFEC by the NYU Metro Center, therefore results may not be generalizable. While family engagement and parent leadership are central to this work, we chose not to include parents or school staff in our data sample. The field of family engagement called for more research to explore the successes and challenges of developing a transformational community-based model of family engagement (Mapp and Bergman 2021). We wanted this paper to address this need by reflecting on the experiences of partners as they built a statewide model of family engagement. Future publications on the KY Collaborative will include the voices of families and educators.

\section{Conclusions}

In this paper we sought to better understand how the KY Collaborative, via a statewide community-based collective impact model, promotes and implements systemic evidencedbased family engagement strategies. Our findings help to illuminate the success and challenges of the KY Collaborative as they shift local, regional, and statewide culture, norms, policies, and practices. We anticipate that other statewide family engagement centers and other community-based collaborations for transformational family engagement can benefit from understanding how the KY Collaborative develops bottom-up leadership, builds dual capacity, shifts power, attends to policy change, and diffuses shared messages, visions, and practices statewide.

Author Contributions: D.M.P. contributed to the conceptualization of the paper, data collection and formal analysis, management of data quality, as well as preparation of the original draft (writing abstract, methods, findings, discussion, and conclusion). J.G. wrote the introduction and literature review and implications sections, as well as conducted close editing of multiple drafts. All authors have read and agreed to the published version of the manuscript.

Funding: Funding for the KY Collaborative is provided by the U.S. Department of Education Statewide Family Engagement Centers (SFEC) Program. Funding for this evaluation is sponsored by the Prichard Committee for Academic Excellence, via their SFEC grant.

Data Availability Statement: Data collected by the documentation are not publicly available. Information on the KY Collaborative and partner organizations can be found at prichardcommittee.org/familyengagement/.

Acknowledgments: The authors would like to acknowledge the KY Collaborative partners, families, and community members for their participation in this work. We would also like to thank Katie Lim and all the project consultants for their contributions to the project.

Conflicts of Interest: The authors declare no conflict of interest.

\section{References}

Anyon, Jean. 2005. What "counts" as educational policy? Notes toward a new paradigm. Harvard Educational Review 75: 65-88. [CrossRef]

Berkowitz, Bill. 2001. Studying the outcomes of community-based coalitions. American Journal of Community Psychology 29: 213-27. [CrossRef] [PubMed] 
Bernard, H. Russell, and Gery W. Ryan. 2010. Analyzing Qualitative Data: Systematic Approaches. Los Angeles: Sage.

Chaskin, Robert J. 2001. Building community capacity: A definitional framework and case studies from a comprehensive community initiative. Urban Affairs Review 36: 291-323. [CrossRef]

Christens, Brian D., and Paula Tran Inzeo. 2015. Widening the view: Situating collective impact among frameworks for community-led change. Community Development 46: 420-35. [CrossRef]

Creswell, John W. 2013. Steps in Conducting a Scholarly Mixed Methods Study. Available online: https://digitalcommons.unl.edu/ dberspeakers / 48/ (accessed on 31 July 2021).

Geller, Joanna D., ed. 2016. Bringing Transformative Family Engagement to Scale: Implementation Lessons from Federal i3 Grants. Providence: Annenberg Institute for School Reform.

Henderson, Anne T., Karen L. Mapp, Vivian R. Johnson, and David Davies. 2007. Beyond the Bake Sale: The Essential Guide to Family-School Partnerships. New York: The New Press.

Ishimaru, Ann M. 2019. From family engagement to equitable collaboration. Educational Policy 33: 350-85. [CrossRef]

Ishimaru, Ann M. 2020. Just Schools: Building Equitable Collaborations with Families and Communities. New York: Teachers College Press.

Ishimaru, Ann M., and Sola Takahashi. 2017. Disrupting racialized institutional scripts: Toward parent-teacher transformative agency for educational justice. Peabody Journal of Education 92: 343-62. [CrossRef]

Kadushin, Charles, Matthew Lindholm, Dan Ryan, Archie Brodsky, and Leonoard Saxe. 2005. Why it is so difficult to form effective community coalitions. City $\mathcal{E}$ Community 4: 255-75.

Kania, John, and Mark Kramer. 2011. Collective Impact. Boston: FSG, pp. 36-41.

Kroll, Janet, Robert F. Sexton, Beverly N. Raimondo, H. Dickson Corbett, and Bruce Wilson. 2001. Setting the Stage for Success: Bringing Parents into Education Reform as Advocates for Higher Student Achievement. A Report on Lessons Learned from the Commonwealth Institute for Parent Leadership of the Prichard Committee for Academic Excellence. Returning Results. Lexington: Prichard Committee for Academic Excellence.

Kubisch, Anne C., Patricia Auspos, Prudence Brown, and Tom Dewar. 2010. Voices from the Field III: Lessons and Challenges from Two Decades of Community Change Efforts. Washington, DC: Aspen Institute.

Ladson-Billings, Gloria. 1995. Toward a Theory of Culturally Relevant Pedagogy. American Educational Research Journal 32: 465-91. [CrossRef]

Lincoln, Yvonna S., and Egon G. Guba. 1985. Naturalistic Inquiry. Los Angeles: Sage.

Lincoln, Yvonna S., and Norman K. Denzin, eds. 2003. Turning Points in Qualitative Research: Tying Knots in a Handkerchief. Lanham: Rowman Altamira, vol. 2.

Mapp, Karen L., and E. Bergman. 2019. Dual-Capacity-Building Framework for Family-School Partnerships (Version 2). Dual-Capacity. Available online: www.dualcapacity.org (accessed on 31 July 2021).

Mapp, Karen L., and Eyal Bergman. 2021. Embracing a New Normal: Toward a More Liberatory Approach to Family Engagement. Available online: https://media.carnegie.org/filer_public/f6/04/f604e672-1d4b-4dc3-903d-3b619a00cd01/fe_report_fin.pdf (accessed on 31 July 2021).

Maxwell, Joseph A. 2013. Qualitative Research Design. An Interactive Approach, 3rd ed. Los Angeles: Sage.

Mcknight, John. 1995. The Careless Society: Community and Its Counterfeits. New York: Basic Books.

McWayne, Christine M., Fabienne Doucet, and Jayanthia Mistry. 2019. Family-school partnerships in ethnocultural communities: Reorienting conceptual frameworks, research methods, and intervention efforts by rotating our lens. In Ethnocultural Diversity and the Home-to-School Link. Cham: Springer, pp. 1-18.

Moll, Luis C., Cathy Amanti, Deborah Neff, and Norma Gonzalez. 1992. Funds of Knowledge for Teaching: Using a Qualitative Approach to Connect Homes and Classrooms. Theory into Practice 31: 132-41. [CrossRef]

Montemayor, Aurelio. 2019. Family Engagement for School Reform. San Antonio: Intercultural Development Research Association.

ORS Impact. 2018. When Collective Impact Has an Impact. Denver: Spark Policy Institute.

Paris, Django. 2012. Culturally Sustaining Pedagogy: A Needed Change in Stance, Terminology, and Practice. Educational Researcher 41: 93-97. [CrossRef]

Patton, Michael Q. 1990. Qualitative Evaluation and Research Methods. New York: SAGE Publications, Inc.

Payne, Charles M. 2008. So Much Reform, so Little Change: The Persistence of Failure in Urban Schools. Cambridge: Harvard Education Press.

Saldaña, Johnny, and Matt Omasta. 2016. Qualitative Research: Analyzing Life. New York: Sage Publications.

Smrekar, Claire E., and Heather B. Mawhinney. 1999. Integrated services: Challenges in linking schools, families, and communities. Handbook of Research on Educational Administration 2: 443-61.

Stone, Wendy. 2001. Measuring social capital. In Australian Institute of Family Studies Research Paper. p. 24. Available online: http:/ / www.cedarscenter.org/resources/Measuring_Social_Capital.pdf (accessed on 31 July 2021).

The Prichard Committee. 2021. Kentucky's Statewide Family Engagement Center. Available online: https:// prichardcommittee.org/ familyengagement/ (accessed on 31 July 2021).

Tyack, David. 1992. Health and social services in public schools: Historical perspectives. The Future of Children 2: 19-31. [CrossRef]

Warren, Mark, and Karen Mapp. 2011. A Match on Dry Grass: Community Organizing as a Catalyst for School Reform. Oxford: The Oxford University Press.

Warren, Mark, Soo Hong, Carolyn Leung Rubin, and Phitsamay Sychitkokhong Uy. 2009. Beyond the bake sale: A community-based relational approach to parent engagement in schools. Teachers College Record 111: 2209-54. 
Wehlage, Gary, Gregory Smith, and Pauline Lipman. 1992. Restructuring urban schools: The new futures experience. American Educational Research Journal 29: 51-93. [CrossRef]

Weiss, Heather, Elena Lopez, and Margaret Caspe. 2018. Carnegie Challenge Paper: Joining Together to Create a Bold Vision for Next Generation Family Engagement. Boston: Global Family Research Project.

Wolfe, Susan M., Pamela D. Long, and Kyrah K. Brown. 2020. Using a Principles-Focused evaluation approach to evaluate coalitions and Collaboratives working toward equity and social justice. New Directions for Evaluation 2020: 45-65. [CrossRef] 